\title{
Radionuclides in the Environment in Switzerland: A Retrospective Study of Transfer from Soil to the Human Body
}

\author{
Pascal Froidevaux*, Pierre-André Pittet, Ruslan Cusnir, François Bochud, and Marietta Straub
}

\begin{abstract}
Natural radionuclides are ubiquitous in the environment. In addition, artificial radionuclides are present in the Swiss environment after the fallout of the nuclear bomb tests of the 1950s and 1960s, after the accident of the Chernobyl nuclear power plant, or after authorized discharges from the Swiss nuclear power plants and research centres. These radionuclides can create a radiological hazard to the environment and humans because of the increased risk of cancer due to the ionizing radiation they produce. Here we show that some of these radionuclides have made their way from the air or the soil to the human body, where they target mostly the skeleton. However, the activity levels of ${ }^{90} \mathrm{Sr},{ }^{239} \mathrm{Pu}$ and ${ }^{240} \mathrm{Pu},{ }^{226} \mathrm{Ra}$ and ${ }^{210} \mathrm{~Pb} /{ }^{210} \mathrm{Po}$ found in the human body remain very low and do not represent a public health issue at the current body burden.
\end{abstract}

Keywords: Environment · Human body $\cdot$ Radiation dose $\cdot$ Radionuclides $\cdot$ Transfer factors

Pascal Froidevaux is a senior scientist and chemist at the Institute of Radiation Physics (IRA) of the University Hospital, Lausanne. He obtained his $\mathrm{PhD}$ in chemistry under the supervision of J.-C. Bünzli from the University of Lausanne. He was a postdoctoral researcher at the University of Western Australia from 1995 to 1997 . Since 1998, he is working as an (radio)analytical chemist in the field of radioecology at the Institute of Radiation Physics. His research interests include radionuclides analysis, radionuclides mobility and bioavailability, the impact of radionuclides to human and the development of solid phase extraction resins to analyse radionuclides.

Pierre-André Pittet is a scientist at the Institute of Radiation Physics of the University Hospital, Lausanne. After obtaining a $\mathrm{PhD}$ in Science at University of Lausanne and one-year postdoctoral research in the field of bioinorganic chemistry, he joined the pharmaceutical industry as an analytical chemist. During that period in drug discovery research, his main interests were the elucidation of structures by NMR, the determination of metabolites by LC-MS and quantitative analyses by LC-MS/MS. Since 2014, he is a scientific collaborator at IRA, in charge of radioanalyses of environmental samples. His current interest is the automation of radioanalytical separations.

Ruslan Cusnir is a research and development radiochemist at the Institute of Radiation Physics of the University Hospital of Lausanne. Trained as analytical radiochemist, he obtained his $\mathrm{PhD}$ in Life Sciences from the University of Lausanne under the supervision of P. Froidevaux. From 2016 to 2019 he was a postdoctoral researcher in the Department of Imaging Chemistry and Biology at the King's College London, funded by a mobility fellowship from the SNSF. After a short return phase in the Radionuclide Development Group at the Paul Scherrer Institute, he joined the Chemical Radioanalytical Group as a scientist. His interests encompass chemical separation of radionuclides, translational radiochemistry and radiation protection.

${ }^{*}$ Correspondence: Dr. P. Froidevaux, E-mail: pascal.froidevaux@chuv.ch Institute of Radiation Physics, Lausanne University Hospital and University of Lausanne, Grand Pré 1, CH-1007 Lausanne, Switzerland
François Bochud is director of the Institute of Radiation Physics at Lausanne University Hospital and professor of medical physics at Lausanne University Hospital. He is a board-certified medical physicist, specialized in radiation protection and radiation metrology. He is president of the Swiss Federal Commission on Radiological Protection, as well as a member of the International Commission on Radiological Protection, Committee 4.

Marietta Straub is the head of the chemical radioanalytical group at the Institute of Radiation Physics of the University Hospital, Lausanne. She got her PhD in Science at ETHZ within a collaboration with Princeton University. After her PhD, she joined IRA as a scientific collaborator in the radioecological group. Two years later, she was appointed group leader of the chemical radiopharmaceutical group. From 2015-2016 she was responsible for the radiopharmaceutical production of radionuclides for the nuclear medicine department of the CHUV. Later, she focused her group on developments of incorporation measurements and mandates with the FOPH and Swissmedic for radipharmaceutical quality assurance in Switzerland. In 2020, she was appointed head of the chemical radioanalytical group at the Institute of Radiation Physics of the University Hospital, Lausanne. Her research interests include radiopharmacy and radionuclides analysis.

\section{Introduction}

Natural and artificial radionuclides are unstable chemical elements which disintegrate with emission of ionising radiation. $\gamma$-Radiation is the most studied because, as a photonic radiation, it can be measured directly with dedicated instruments. ${ }^{137} \mathrm{Cs}$ produced during nuclear fission is a typical $\gamma$-emitting radionuclide that has been widely studied in the context of nuclear accidents such as Chernobyl and Fukushima. ${ }^{[1]}$ On the other hand, $\beta$-decay only produces electrons (and antineutrinos). These electrons are difficult to measure and $\beta$-emitting radionuclides require a complex chemical separation to reach satisfactory detection limits during analysis. This is why $\beta$-emitting radionuclides are monitored to a lesser extent in the framework of a radiation survey plan. However, $\beta$-emitting radionuclides such as ${ }^{90} \mathrm{Sr}$, also a result of nuclear fission, can be very damaging to human because of their high mobility in the environment. ${ }^{[2]}$ As an alkaline-earth cation 
similar to calcium, ${ }^{90} \mathrm{Sr}$ targets bones and deposits its energetic $\beta$-radiation in the proximity to the bone marrow. ${ }^{[3]}$ In this context, ${ }^{90} \mathrm{Sr}$ should be systematically determined where nuclear fission is of concern. $\alpha$-Radiation is the most damaging radiation for living species. The dose factor for $\alpha$-radiation is typically 20 times higher than for a $\gamma$-radiation. The $\alpha$-particle deposits its energy within a few $\mu \mathrm{m}$ from the source point, creating numerous damaging ionisations along the track. $\alpha$-Emitting radionuclides represent a significant threat for human tissues through inhalation or ingestion. ${ }^{239} \mathrm{Pu}$ and ${ }^{240} \mathrm{Pu}$ belong to radionuclides from the $\alpha$-emitters family. They are also difficult to determine for reasons similar to those of $\beta$-radiation. Natural radionuclides such as ${ }^{238} \mathrm{U},{ }^{235} \mathrm{U}$ or ${ }^{232} \mathrm{Th}$ are also $\alpha$-emitters. During disintegration, they give off a series of unstable daughter nuclides, either $\beta$-, $\gamma$ - or $\alpha$-emitters. Each series contains at least 20 radioactive members, which decay consecutively to a final stable nuclide - an isotope of lead.

The danger represented by a radionuclide is not only related to its decay mode, $\alpha$-emitters being more deleterious than $\beta$ - and $\gamma$-emitters, but mostly to its capability to be transferred from the soil, where it is deposited, to the human food chain. ${ }^{[2,4]}$ In this respect, the chemical properties of a given radionuclide are more important than its decay mode. Radionuclides that have similar chemical properties to those of stable elements involved in biological metabolism can cross biological membranes. ${ }^{[2 \mathrm{e}]}$ For instance, $\mathrm{K}^{+}$is an alkaline cation of importance in the living species metabolism. Thus, ${ }^{137} \mathrm{Cs}$, as an alkaline cation, is able to cross biological membranes as a side effect of K-metabolism, even if Cs has no significant role in the metabolism. In humans, $\mathrm{K}$ is mostly found in muscles, as ${ }^{137} \mathrm{Cs}$ will be. One of the most radiotoxic elements from the nuclear industry is ${ }^{90} \mathrm{Sr}$. As an alkaline-earth cation, it follows $\mathrm{Ca}$ all along the $\mathrm{Ca}$ metabolism, targeting bones. Likewise, natural ${ }^{226} \mathrm{Ra}$ and its progeny ${ }^{210} \mathrm{~Pb}$ behave in a similar way. ${ }^{[5]}$ Even if $\mathrm{Pb}^{2+}$ is not directly related to the alkaline-earth cation family, its biokinetics in human is very similar to $\mathrm{Ca}^{2+} .{ }^{[6]}$ Once incorporated into the bone structure as $\mathrm{Ca}(\mathrm{Pb})$-hydroxyapatite, it decays to ${ }^{210} \mathrm{Bi}$, a very energetic $\beta$-emitter, and to the very radiotoxic $\alpha$-emitter ${ }^{210} \mathrm{Po} .[3 \mathrm{c}, \mathrm{d}, 7]$ In this study, we show that ${ }^{90} \mathrm{Sr}$, deposited in the Swiss environment because of the nuclear bomb tests fallout, is easily transferred from soil to plants, to milk and human bones, following the Ca metabolism pathway. Similarly, ${ }^{90} \mathrm{Sr}$ found in milk teeth, which form already in utero during pregnancy, shows that ${ }^{90} \mathrm{Sr}$ can cross the placental barrier.[3a,b,8] We also were able to quantify ${ }^{226} \mathrm{Ra}$ and ${ }^{210} \mathrm{Po}$ in human vertebrae, because $\mathrm{Ra}$ is a member of the alkaline-earth cations family, and ${ }^{210} \mathrm{Po}$ is the progeny of ${ }^{210} \mathrm{~Pb}$, an element with similar metabolism as $\mathrm{Ca}$. On the other hand, we demonstrate that $\mathrm{Pu}$ cannot cross the placental barrier, because we did not find significant quantity of the $\mathrm{Pu}$ present in air during the fallout of the nuclear bomb tests in milk teeth formed during pregnancy. Following $\mathrm{Pu}$ deposition and integration in soils, no transfer to the food chain and human was observed and no $\mathrm{Pu}$ was found in human vertebrae of persons born after 1967.

\section{Experimental}

All the samples measured in this study come from the National Radioactivity Survey Plan of the Swiss Federal Office of Public Health and have been analysed for this purpose. From 1971 to $2004,{ }^{90} \mathrm{Sr}$ has been determined as described by Froidevaux et $a l .{ }^{[3 b]}$ From 2004 to $2010,{ }^{90} \mathrm{Sr}$ has been determined as described by Guillaume et al.[2e] and, starting from 2010, with a specific ion-imprinted polymer as described by Chauvin et $a .{ }^{[9]}$ and Froidevaux et al..$^{[10]}{ }^{239+240} \mathrm{Pu}$ was determined by alpha spectrometry as described in Luisier et al.[11] ${ }^{239} \mathrm{Pu}$ in bone and teeth was determined by mass spectrometry as described by Froidevaux and Haldimann ${ }^{[8]}$ and Froidevaux et al. ${ }^{[3 \mathrm{a}]}{ }^{226} \mathrm{Ra}$ in bones was determined as described by Straub et al..$^{[5]}{ }^{210} \mathrm{Po}$ was determined in vertebrae as described by Froidevaux et al. ${ }^{[7]}$
Transfer factors are expressed as the ratio of compartment 1 (in a given unit) to the compartment 2. Eqns (1) to (3) show the different expression for ${ }^{90} \mathrm{Sr}$ transfer factor from soil to grass, grass to milk and milk-to-milk teeth and bones.

$$
T F_{\text {sol-grass }}=\frac{A_{\text {grass }}\left[\frac{B q}{k g}\right]}{A_{\text {soil }}\left[\frac{B q}{k g}\right]}
$$

$$
T F_{\text {grass-milk }}=\frac{A_{\text {milk }}\left[\frac{B q}{g C a}\right]}{A_{\text {grass }}\left[\frac{B q}{k g}\right]}
$$

$$
T F_{\text {milk-milk teeth }}=\frac{A_{\text {milk-teeth }}\left[\frac{B q}{g C a}\right]}{A_{\text {milk }}\left[\frac{B q}{g C a}\right]}
$$

\section{Results and Discussion}

\section{1 ${ }^{90} \mathrm{Sr}$ Transfer from Soil to Human}

${ }^{90} \mathrm{Sr}$ is present in the Swiss environment mostly because of the nuclear bomb tests fallout of the 1960s and marginally as the consequence of the Chernobyl accident. Results of numerous ${ }^{90} \mathrm{Sr}$ analyses from the 1960s up to now show that ${ }^{90} \mathrm{Sr}$ was transferred from the soil to the human food chain and to the skeleton. ${ }^{[3 a-c]}$ Fig. 1 displays the results obtained in Switzerland for soil, grass, wheat, milk, milk teeth and vertebrae. Each single value in Fig. 1 is the average of the yearly determination of about 20 soil samples, 20 grass samples collected above the soil samples, 15 wheat samples, 20 milk samples, 12 vertebrae from 12 different individuals collected mostly by the Lausanne and the Lugano pathology institutes and 12 milk teeth samples. A milk tooth sample is formed by merging at least 10 teeth from children born the same year. ${ }^{[3 b]}$ The main feature of Fig. 1 shows that ${ }^{90} \mathrm{Sr}$ has decreased from 1965, after the nuclear test ban treaty, in all the measured compartments with the same biological half-life, close to $13.1 \pm$ $2 \mathrm{y}$. The soil is the compartment that directs the mechanism of transfer to the food chain. The biological half-life of ${ }^{90} \mathrm{Sr}$ in the root zone (rhizosphere) of soil is $12.6 \mathrm{y}$. It follows that the biological half-life of the other compartments is linked to that of soil.

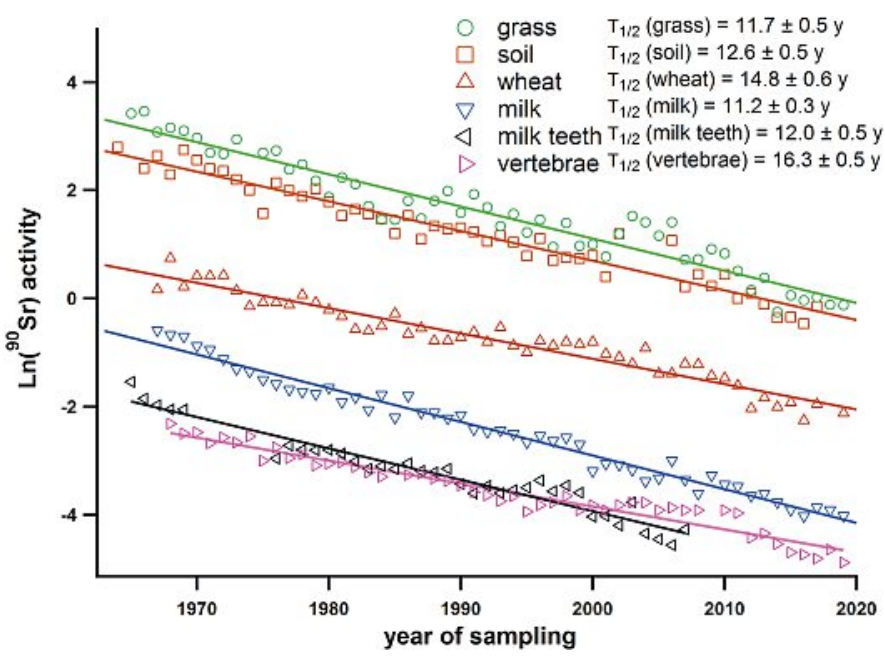

Fig. 1. Logarithm of the ${ }^{90} \mathrm{Sr}$ activities, in $\mathrm{Bq} \mathrm{kg}{ }^{-1}$ for soil, grass and wheat and in $\mathrm{Bq} \mathrm{g} \mathrm{Ca}^{-1}$ for milk, milk teeth and vertebrae, and related biological half-life for the environment of the Swiss Tableland. 
Because the half-lives are the same for all measured compartments, it is possible to calculate the transfer from one compartment to another with the concept of the transfer factor. The transfer factor (TF) links two compartments with a simple relationship. It does not reveal the geochemical mechanism or biological mechanism of transfer. Nevertheless, it allows a rapid evaluation of the possible consequence of a radioactive contamination for a given radionuclide if sufficient data are available to produce a histogram of the TF values. For instance, the histogram of TF values for ${ }^{90} \mathrm{Sr}$ from soil to grass in Switzerland based on the data of Fig. $1(\mathrm{n}=$ 53 ) shows that the values are centred on $\mathrm{TF}=1.3$. Table 1 gives the $\mathrm{TF}$ values for ${ }^{90} \mathrm{Sr}$ from soil to human, based on our data set of values collected from 1965 to now. TF values less than 1 for the transfer from milk to milk teeth and vertebrae show that the human metabolism makes a preference for $\mathrm{Ca}$ over $\mathrm{Sr}$; the latter having no known role in human metabolism.

Table 1. TF values for ${ }^{90} \mathrm{Sr}$ in the Swiss environment. Compartments taken into account are soil, grass, wheat, milk, milk teeth and vertebrae. TF are evaluated as histogram values based on data of Fig. $1(n=53)$.

\begin{tabular}{|l|l|}
\hline Compartments & TF value $\pm \mathbf{u}(\mathbf{k}=\mathbf{1})$ \\
\hline soil $\rightarrow$ grass & $1.3 \pm 10 \%$ \\
\hline soil $\rightarrow$ wheat & $0.15 \pm 25 \%$ \\
\hline grass $\rightarrow$ milk & $0.02 \pm 20 \% \mathrm{~kg} \mathrm{~g} \mathrm{Ca}^{-1}$ \\
\hline milk $\rightarrow$ milk teeth & $0.33 \pm 25 \%$ \\
\hline milk $\rightarrow$ vertebrae & $0.35 \pm 25 \%$ \\
\hline
\end{tabular}

Fig. 2 shows the pulse of ${ }^{90} \mathrm{Sr}$ activity measured in Switzerland during and after the fallout of the nuclear bomb tests of the 1950s and $1960 \mathrm{~s}$. The activity profile of ${ }^{90} \mathrm{Sr}$ in milk teeth matches perfectly the one for milk. Considering that the enamel of milk teeth forms during pregnancy and during breast-feeding, these results demonstrate that ${ }^{90} \mathrm{Sr}$ has crossed the placental barrier. ${ }^{[3 \mathrm{~b}, 8]}$ The ${ }^{90} \mathrm{Sr}$ profile in human vertebrae also matches the one of milk, but with a delay of about 2 years. This delay is the result of the bone-remodelling rate, which recirculates the $\mathrm{Ca}$ in the organism, incorporating new $\mathrm{Ca}\left({ }^{90} \mathrm{Sr}\right)$ in the bone structure. The bone-remodelling rate is dependent on age, bone functionalities and varies between individuals. It is faster at younger ages and for trabecular bones such as vertebrae. While our database contains samples from individuals deceased mostly after 60 years (80\%) and none who died before 8 years, the results show that ${ }^{90} \mathrm{Sr}$ was readily incorporated into the bone structure. ${ }^{[3 \mathrm{a}]}$ Similar to milk teeth, ${ }^{90} \mathrm{Sr}$ is rapidly incorporated into the skeleton of the foetus and newborns. Thus, our data show that ${ }^{90} \mathrm{Sr}$ is very mobile in the environment, easily transferred to the food chain, and reaches through placental

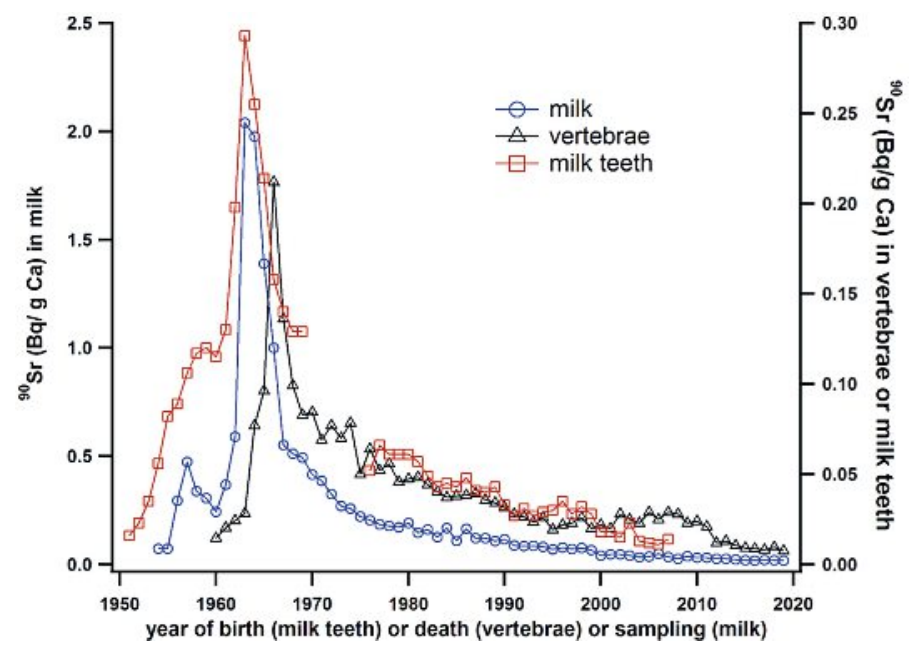

Fig. 2. ${ }^{90} \mathrm{Sr}$ activity profiles in milk, milk teeth and vertebrae in Switzerland from the beginning of the nuclear era to 2019. The activities of milk teeth are reported to the year of birth and the activities of vertebrae to the year of death.

transfer the skeleton and milk teeth of the foetus. In this respect, pregnant women should be particularly protected against this particular radionuclide.

\section{2 ${ }^{226} \mathrm{Ra}$ and ${ }^{210} \mathrm{Po}$ Transfer to Humans}

${ }^{226} \mathrm{Ra}$ and ${ }^{210} \mathrm{Po}$ belong to the decay series of ${ }^{238} \mathrm{U}$, which is present in soil at an average activity of $30 \mathrm{~Bq} \mathrm{~kg}^{-1}$. However, it can be accumulated in wetlands to exceptional values above 100'000 $\mathrm{Bq} \mathrm{kg}^{-1}$.[12] ${ }^{226} \mathrm{Ra}$ is the seventh member of the series and has a long half-life of $1602 \mathrm{y}$. As an alkaline-earth cation, it is rather mobile and, in a way similar to $\mathrm{Sr}$, it can be transferred from soil to human. ${ }^{226} \mathrm{Ra}$ has been used in the Swiss watch industry and can be present in excess in the Swiss environment as a radioactive heritage of the past. In 2015, the Swiss Federal Office of Public Health launched a program of rehabilitation of contaminated sites in the Jura, Soleure, Neuchâtel and Bienne areas. ${ }^{[13]}$ In this context, it appeared important to establish a database of ${ }^{226} \mathrm{Ra}$ values in bones, using samples collected in the framework of the National Radioactivity Survey Plan for ${ }^{90} \mathrm{Sr}$ measurement. Results of the ${ }^{226} \mathrm{Ra}$ analyses on 33 vertebrae sampled from 2014 to 2019 showed that the accumulated activities are low, with an average of $1.82 \mathrm{mBq} \mathrm{g} \mathrm{Ca}^{-1}$, a minimum value at $0.73 \mathrm{mBq} \mathrm{g} \mathrm{Ca}^{-1}$ and a maximum value at $4.58 \mathrm{mBq} \mathrm{g} \mathrm{Ca}^{-1}$ (Table 2). These value are within or

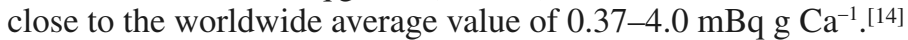

${ }^{210} \mathrm{Po}$ is also a member of the ${ }^{238} \mathrm{U}$ decay series. Its chemistry is more related to the metalloids rather than to metals. ${ }^{210} \mathrm{Po}$ bears a high charge density $(+4)$ leading to fast hydrolysis, even at low $\mathrm{pH}$. In this respect, it is relatively immobile in soil and not easily transferred to the food chain. It has a half-life of 138.4 days and thus, is mostly supported by ${ }^{210} \mathrm{~Pb}\left(\mathrm{~T}_{1 / 2}=22.3 \mathrm{y}\right)$. Secular equilibrium between ${ }^{210} \mathrm{~Pb}$ and ${ }^{210} \mathrm{Po}$ means that the presence of

Table 2. ${ }^{226} \mathrm{Ra},{ }^{210} \mathrm{Po}$ and ${ }^{90} \mathrm{Sr}$ activities $\left(\mathrm{mBq} \mathrm{g} \mathrm{Ca}^{-1}\right)$ in vertebrae of the Swiss population (Tessin and Vaud regions) between 2010 and 2019.

\begin{tabular}{|c|c|}
\hline Radionuclide & Number of cases \\
\hline${ }^{22} \mathrm{Ra}$ & 33 \\
\hline${ }^{210} \mathrm{Po}$ & 80 \\
\hline${ }^{90} \mathrm{Sr}$ & 134 \\
\hline${ }^{239} \mathrm{Pu}^{\mathrm{a}}$ & 42 \\
\hline
\end{tabular}

\section{Average activity [mBq g Ca-1]}

1.82

29.6

12.2

0.054

\section{Minimum activity [mBq $\mathrm{g} \mathrm{Ca}^{-1}$ ]}

0.73

5.95

3.8

0.030

\section{Maximum activity [mBq $\mathrm{g} \mathrm{Ca}^{-1}$ ]}

$$
4.58
$$

101.6

0.086 
${ }^{210} \mathrm{Po}$ in a compartment is due to the presence of ${ }^{210} \mathrm{~Pb}$ in the same compartment. ${ }^{210} \mathrm{~Pb}$ oxidation state in natural environment is +2 , which makes the $\mathrm{Pb}^{2+}$ chemistry rather similar to that of $\mathrm{Ca}^{2+}$. Biokinetics of $\mathrm{Pb}$ is very similar to $\mathrm{Ca}$, thus ${ }^{210} \mathrm{~Pb}$ is found mostly in the skeleton. ${ }^{[6]}$ In this respect, ${ }^{210} \mathrm{Po}$ found in bones reflects the presence of ${ }^{210} \mathrm{~Pb}$ in the skeleton. The results of the analysis of 80 cases since 2006 shows that the distribution of the activity is log-normally distributed, with an average value at $29.6 \mathrm{mBq}$ $\mathrm{g} \mathrm{Ca}^{-1}$ (Fig. 3). The minimum value is $5.9 \mathrm{mBq} \mathrm{g} \mathrm{Ca}^{-1}$ and the maximum value is $101.6 \mathrm{mBq} \mathrm{g} \mathrm{Ca}^{-1}$ (Table 2). The large interval of values covering almost two orders of magnitude reflects the different mechanisms of introduction of ${ }^{210} \mathrm{~Pb} /{ }^{210} \mathrm{Po}$ in the body. As a decay product of the ${ }^{222} \mathrm{Rn}$ gas, ${ }^{210} \mathrm{~Pb}$ can be inhaled in significant quantities in regions with high level of ${ }^{222} \mathrm{Rn}$, such as in the Tessin canton. ${ }^{[15]}$ Seafood consumption is also of concern, as ${ }^{210} \mathrm{~Pb}$ and ${ }^{210} \mathrm{Po}$ are found at higher level in these samples. ${ }^{[16]}$ In addition, tobacco habits are also of concern because ${ }^{210} \mathrm{~Pb}$ and ${ }^{210} \mathrm{Po}$ are found in significant activity in the main stream of tobacco smoke. ${ }^{[17]}$

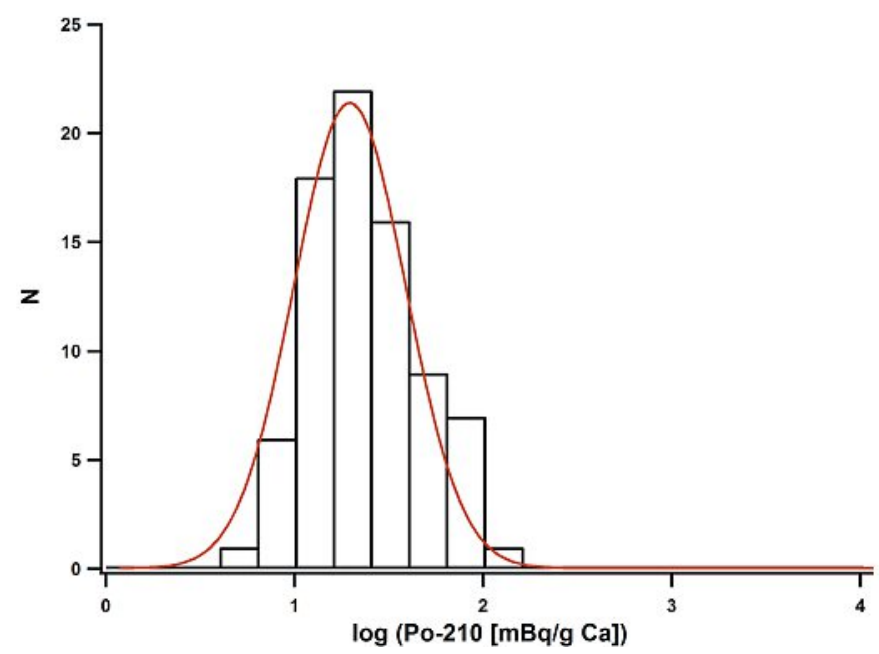

Fig. 3. Distribution of the log $\left({ }^{210} \mathrm{Po}\right)$ activities form the Swiss ${ }^{210} \mathrm{Po}$ database on ${ }^{210} \mathrm{Po}$ content in vertebrae $(n=80)$, showing a log-normal distribution with an average value of $29 \mathrm{mBq} \mathrm{g} \mathrm{Ca}^{-1}$.

\subsection{Plutonium Transfer to Humans}

Plutonium is present in the Swiss environment because of the fallout of the atmospheric nuclear bomb tests of the 1950s and 1960s and to the burn-out of a SNAP-9A satellite (1964), powered by a radioisotope thermoelectric generator (RTG) containing ${ }^{238} \mathrm{Pu}$ $(1 \mathrm{~kg})$. In Switzerland, all the soils measured in the framework of the National Radioactivity Survey Plan contain traces of ${ }^{239+240} \mathrm{Pu}$, ${ }^{238} \mathrm{Pu}$ and ${ }^{241} \mathrm{Am}$ from these events. This results in the determination of a ${ }^{238} \mathrm{Pu} /{ }^{239+240} \mathrm{Pu}$ isotopic ratio of $0.029 \pm 0.001$ and a ${ }^{241} \mathrm{Am} /{ }^{239+240} \mathrm{Pu}$ ratio of $0.424 \pm 0.012$ for soil samples collected from 2015 to 2019 (Fig. 4). Most of the activities of ${ }^{239+240} \mathrm{Pu}$ are below $0.3 \mathrm{~Bq} \mathrm{~kg} \mathrm{~kg}^{-1}$, except for some soils of higher altitude where higher fallout deposition are observed.[18] Two studies were conducted in Switzerland to investigate the fate of $\mathrm{Pu}$ deposited in the environment. In one of these studies, we took advantage of the milk teeth samples collected in the sixties to re-investigate the $\mathrm{Pu}$ content of milk teeth, using modern mass spectrometry techniques. ${ }^{[8]}$ The aim was to use milk teeth to demonstrate that $\mathrm{Pu}$ does not cross the placental barrier. Results showed that ${ }^{239} \mathrm{Pu}$ was found mostly in the root of the milk teeth and peaked in the whole milk teeth at $8 \mu \mathrm{Bq} \mathrm{g} \mathrm{Ca}{ }^{-1}$ for children who were about 10 years old when the ${ }^{239} \mathrm{Pu}$ activity peaked in air (1963). This means that the ${ }^{239} \mathrm{Pu}$ activity in milk teeth was due to inhalation of contaminated air during the sixties, with a transfer to the roots due to the presence of vascularization. Enamel, formed during pregnancy was not impacted and the ratio of the activity of enamel to the activity of the root was $0.10-0.20 .{ }^{[8]}$ Thus, in contrast to ${ }^{90} \mathrm{Sr}$, Pu is not transferred across the placental barrier to the foetus skeleton.

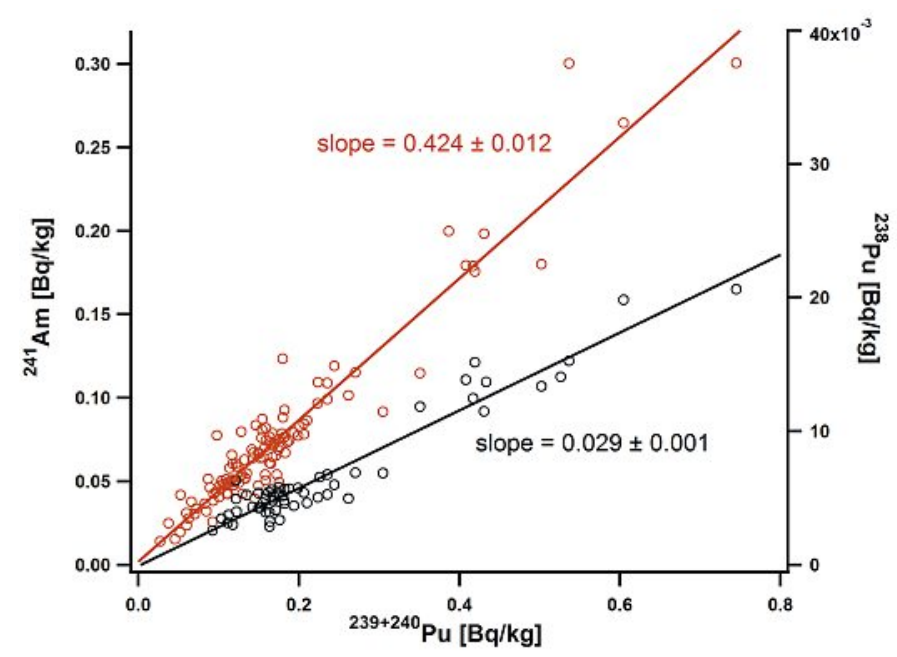

Fig. 4. ${ }^{238} \mathrm{Pu}$ and ${ }^{241} \mathrm{Am}$ activities in function of the ${ }^{239+240} \mathrm{Pu}$ activities of soils sampled from 2015 to 2019 in Switzerland.

${ }^{239} \mathrm{Pu}$ was also found in vertebrae of the Swiss population. ${ }^{[3 \mathrm{a}]}$ Similarly to the case of milk teeth, ${ }^{239} \mathrm{Pu}$ was inhaled during the contamination of the air, which stopped shortly after the nuclear test ban treaty was enforced (1963). From the analyses of our database samples of vertebrae, we found that individuals who died before 1960 had undetectable ${ }^{239} \mathrm{Pu}$ in vertebrae. On the other hand, we also found that individuals who were born after 1970 had undetectable or very low ${ }^{239} \mathrm{Pu}$ activity. In this respect, ${ }^{239} \mathrm{Pu}$ concerns individuals who inhaled contaminated air during the sixties. By measuring vertebrae of individuals who died between 1962 and 2004 , we were able to estimate the retention time of ${ }^{239} \mathrm{Pu}$ in the skeleton of people who inhaled ${ }^{239} \mathrm{Pu}$ before 1967. After 1967, the ${ }^{239} \mathrm{Pu}$ concentration in air was considered negligible. The retention half-life of ${ }^{239} \mathrm{Pu}$ in the skeleton was $40 \pm 14 \mathrm{y}(\mathrm{k}=2) .{ }^{[3 \mathrm{a}]}$ The average activity was $0.054 \mathrm{mBq} / \mathrm{g} \mathrm{Ca}$, a value very close to the $0.048 \mathrm{mBq} \mathrm{g} \mathrm{Ca}^{-1}$ found in the root zone of milk teeth, showing similarity between these two calciferous tissues. ${ }^{[8]}$

\section{Conclusions}

This study demonstrates that some radionuclides, either natural or artificial, are transferred from soil to the food chain and human. The ability of a radionuclide to be transferred depends mostly on its chemistry or, in case of natural radioactivity series, on the chemistry of its parent radionuclides. The very radiotoxic fission product ${ }^{90} \mathrm{Sr}$ is easily transferred to the human skeleton because of its chemical similarity with $\mathrm{Ca}$. However, results show that the human metabolism has a preference of $\mathrm{Ca}$ over $\mathrm{Sr}$, the TF of milk-to-milk teeth and bone being close to 0.3. In addition, results show a much higher preference for $\mathrm{Ca}$ over $\mathrm{Ra}$. This is probably due to the larger cationic radius of $\mathrm{Ra}$ compared to $\mathrm{Ca}$ and $\mathrm{Sr}$, preventing its passage across biological membranes and its introduction into the structure of the apatite of bones and teeth. Thus, $\mathrm{Ra}$ is found in much lower concentration in vertebrae than ${ }^{90} \mathrm{Sr}$, given that the ${ }^{226} \mathrm{Ra}$ activity in soil is currently about 60 times higher than the activity of ${ }^{90} \mathrm{Sr} .{ }^{210} \mathrm{Po}$ is probably not directly transferred to bones but its presence in vertebrae is the consequence of decaying ${ }^{210} \mathrm{~Pb}$ having similar biokinetics as $\mathrm{Ca}$ in human. Even if $\mathrm{Pu}$ does not cross the placental barrier, it is present in detectable activities in vertebrae. In addition, its retention half-life is 40 years, which means that once inhaled, $\mathrm{Pu}$ remains in significant amounts in the human body for a lifetime, causing a potential irradiation danger. While the measured activities of the considered 
radionuclides in this study have become low (Table 2) and do not represent a significant radiation dose to the public, it is necessary to monitor the fate of these radionuclides. The (radio) analytical work of the past 60 years yielded data that form the basis of all numerical modelling of radioactivity transport. Switzerland still has four working nuclear power reactors with another one being currently decommissioned, thus the necessity to detect any potential environmental contamination well deserves the analytical efforts.

\section{Acknowledgements}

The Swiss Federal Office of Public Health and the University of Lausanne funded this work. The authors thank M. Haldimann, J.-J. Geering, P. Steinmann, J.A. Corcho-Alvarado, L. Pfefferlé and F. Barraud for their help in the analytical work.

Received: July 29, 2020

[1] a) Y. Igarashi, Y. Onda, Y. Wakiyama, A. Konoplev, M. Zheleznyak, H. Lisovyi, G. Laptev, V. Damiyanovich, D. Samoilov, K. Nanba, S. Kirieiev, Environ. Pollu. 2020, 259, https://doi.org/10.1016/j.envpol.2019.113764; b) P. R. Li, Y. T. Gong, M. Komatsuzaki, Sci. Total Environ. 2019, 697, https://doi.org/10.1016/j.scitotenv.2019.134060.

[2] a) F. Chawla, P. Steinmann, J. L. Loizeau, M. Hassouna, P. Froidevaux, Environ. Sci. Technol. 2010, 44, 8509, https://doi.org/10.1021/es101766g; b) F. Chawla, P. Steinmann, H. R. Pfeifer, P. Froidevaux, Sci. Total Environ. 2010, 408, 3292, https://doi.org/10.1016/j.scitotenv.2010.03.012; c) P. Froidevaux, J. J. Geering, J. F. Valley, J. Radioanal. Nucl. Chem. 2002, 254, 23, https://doi.org/10.1023/a:1020872910506; d) P. Froidevaux, P. Steinmann, L. Pourcelot, Environ. Sci. Technol. 2010, 44, 8479, https://doi.org/10.1021/es100954h; e) T. Guillaume, F. Chawla, P. Steinmann, J. M. Gobat, P. Froidevaux, Plant and Soil 2012, 355, 29, https://doi.org/10.1007/s11104-011-1110-6.

[3] a) P. Froidevaux, F. Bochud, M. Haldimann, Chemosphere 2010, 80, 519, https://doi.org/10.1016/j.chemosphere.2010.04.049; b) P. Froidevaux, J. J. Geering, J. F. Valley, Sci. Total Environ. 2006, 367, 596, https://doi.org/10.1016/j.scitotenv.2006.02.011; c) B. Schrag, T. Uldin, P. Mangin, F. Bochud, P. Froidevaux, Forensic Sci. Int. 2014, 234, https://doi.org/10.1016/j.forsciint.2013.10.038; d) B. Schrag, T. Uldin, P. Mangin, P. Froidevaux, Forensic Sci. Int. 2012, 220, 271, https://doi.org/10.1016/j.forsciint.2012.03.014.

[4] L. Pillonel, R. Badertscher, P. Froidevaux, G. Haberhauer, S. Holzl, P. Horn, A. Jakob, E. Pfammatter, U. Piantini, A. Rossmann, R. Tabacchi, J. O. Bosset, Lebensmittel-Wissenschaft Und-Technologie-Food Science and Technology 2003, 36, 615, https://doi.org/10.1016/s0023-6438(03)00081-1.
[5] M. Straub, P. A. Pittet, G. Amzalag, F. Bochud, S. Baechler, P. Froidevaux, Anal. Chim. Acta 2018, 1031, 178, https://doi.org/10.1016/j.aca.2018.05.007.

[6] R. W. Leggett, Environ. Health Perspect. 1993, 101, 598, https://doi.org/10.2307/3431645.

[7] P. Froidevaux, F. Bochud, S. Baechler, V. Castella, M. Augsburger, C. Bailat, K. Michaud, M. Straub, M. Pecchia, T. M. Jenk, T. Uldin, P. Mangin, Forensic Sci. Int. 2016, 259, 1, https://doi.org/10.1016/j.forsciint.2015.09.019.

[8] P. Froidevaux, M. Haldimann, Environ. Health Perspect. 2008, 116, 1731, https://doi.org/10.1289/ehp.11358.

[9] A. S. Chauvin, J. C. G. Bunzli, F. Bochud, R. Scopelliti, P. Froidevaux, Chem. Eur. J. 2006, 12, 6852, https://doi.org/10.1002/chem.200501370.

[10] P. Froidevaux, S. Happel, A. S. Chauvin, Chimia 2006, 60, 203, https://doi.org/10.2533/000942906777674895.

[11] F. Luisier, J. A. C. Alvarado, P. Steinmann, M. Krachler, P. Froidevaux, J. Radioanal. Nucl. Chem. 2009, 281, 425, https://doi.org/10.1007/s10967-009-0004-z.

[12] J. Pena, M. Straub, V. Flury, E. Loup, J. Corcho, P. Steinmann, F. Bochud, P. Froidevaux, Sci. Total Environ. 2020, 727, https://doi.org/10.1016/j.scitotenv.2020.138368.

[13] OPFSP, Plan d'action radium 2015 à 2019, www.bag.admin.ch .

[14] A. I. Lovaas, J. B. Hursh, Health Phys. 1968, 14, 549, https://doi.org/10.1097/00004032-196806000-00002.

[15] a) G. Kropat, F. Bochud, M. Jaboyedoff, J. P. Laedermann, C. Murith, M. Palacios, S. Baechler, J. Environ. Radioact. 2015, 147, 51, https://doi.org/10.1016/j.jenvrad.2015.05.006; b) G. Kropat, F. Bochud, M. Jaboyedoff, J. P. Laedermann, C. Murith, M. Palacios, S. Baechler, Sci. Total Environ. 2015, 505, 137, https://doi.org/10.1016/j.scitotenv.2014.09.064.

[16] a) A. J. Pearson, S. Gaw, N. Hermanspahn, C. N. Glover, J. Environ. Radioact. 2016, 151, 542, https://doi.org/10.1016/j.jenvrad.2015.07.026; b) P. Renaud, S. Roussel-Debet, L. Pourcelot, H. Thebault, J. Loyen, R. Gurriaran, Radioprot. 2015, 50, 123, https://doi.org/10.1051/radiopro/2014039.

[17] a) M. Horvath, A. Shahrokhi, P. Bator, E. Toth-Bodrogi, T. Kovacs, J. Environ Radioact. 2017, 174, 66, https://doi.org/10.1016/j.jenvrad.2017.01.023; b) T. H. Winters, J. R. Difranza, New Engl. J. Med. 1982, 306, 364.

[18] L. Pourcelot, P. Steinmann, P. Froidevaux, Chemosphere 2007, 66, 1571 , https://doi.org/10.1016/j.chemosphere.2006.08.008.

\section{License and Terms}

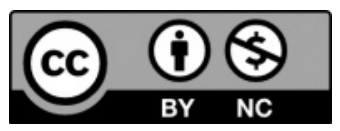

This is an Open Access article under the terms of the Creative Commons Attribution License CC BY_NC 4.0. The material may not be used for commercial purposes.

The license is subject to the CHIMIA terms and conditions: (http:// chimia.ch/component/sppagebuilder/?view=page \&id=12).

The definitive version of this article is the electronic one that can be found at https://doi.org/10.2533/chimia.2020.984 